\title{
Daytime sleepiness, cognitive performance and mood after continuous positive airway pressure for the sleep apnoea/hypopnoea syndrome
}

\author{
Heather M Engleman, Katherine E Cheshire, Ian J Deary, Neil J Douglas
}

\begin{abstract}
Background-Patients with the sleep apnoea/hypopnoea syndrome often receive continuous positive airway pressure to improve their symptoms and daytime performance, yet objective evidence of the effect of this treatment on cognitive performance is lacking.

Methods-A prospective parallel group study was performed comparing the change in objective daytime sleepiness as assessed by multiple sleep latency, cognitive function, and mood in 21 patients (mean (SE) number of apnoeas and hypopnoeas/hour 57 (6)) who received continuous positive airway pressure for three months and 16 patients (49(6) apnoeas and hypopnoeas/hour) who received conservative treatment for a similar period.
\end{abstract}

Results-Both groups showed significant within group changes in cognitive function between baseline and three months, but when comparisons were made between groups the only significant difference was a greater improvement in multiple sleep latency with continuous positive airway pressure. However, the improvement in sleep latency with continuous positive airway pressure was relatively small $(3.5(0.5)$ to $5.6(0.7) \mathrm{min})$. The group treated with continuous positive airway pressure was divided into those who complied well with treatment (>4.5 hours/night) and those who did not. Those who complied well $(n=14)$ showed significant improvement in mean sleep latency and also in depression score compared with the controls but no greater improvement in cognitive function.

Conclusion-This study confirms significant improvements in objective sleepiness and mood with continuous positive airway pressure, but shows no evidence of major improvements in cognitive function.

(Thorax 1993;48:911-914)

Daytime sleepiness, impaired daytime performance and lowered mood are common symptoms of the sleep apnoea/hypopnoea syndrome, and there is objective evidence of daytime sleepiness and impaired cognitive performance in these patients. ${ }^{1-3}$ Treatment with continuous positive airway pressure has been shown to improve nocturnal breathing pattern, ${ }^{4}$ nocturnal sleep quality, ${ }^{5}$ objective daytime sleepiness, ${ }^{6}$ and also mood. $^{7}$ Although patients with the sleep apnoea/ hypopnoea syndrome frequently report improvements in subjective daytime function with continuous positive airway pressure, objective confirmation of its effect on cognitive function is lacking. We therefore conducted a controlled trial to assess changes in cognitive performance, mood and daytime sleepiness in such patients after treatment.

\section{Methods}

A prospective parallel group study was performed comparing the change in cognitive function, mood and objective daytime sleepiness after at least three months (mean (SE) 6 (1) months) of treatment with either continuous positive airway pressure or conservative treatment only. Each patient gave written informed consent to the study, which had the approval of the local ethical advisory committee.

All patients underwent an overnight sleep study to confirm the diagnosis of the sleep apnoea/hypopnoea syndrome, defined as having more than 15 apnoeas and hypopnoeas per hour of sleep. ${ }^{8}$ Polysomnography was performed using our standard techniques ${ }^{9}$ with monitoring of electroencephalography (EEG), electro-oculography and electromyography, thoracic and abdominal movement by inductance plethysmography, oronasal flow with a thermocouple, and oxygen saturation by ear oximetry (Ohmeda Biox 3700). An apnoea was defined as a cessation of airflow for 10 seconds or more, and a hypopnoea as a reduction in thoracoabdominal movement of $50 \%$ or more for 10 seconds or longer. ${ }^{8}$ Sleep was scored by conventional criteria $^{10}$ and arousals were scored when there was a rise in electromyographic activity during sleep coincident with return of $a$ or $\theta$ EEG activity for at least 1.5 seconds. ${ }^{11}$ Patients receiving continuous positive airway pressure underwent a further overnight sleep study in which the pressure was titrated to a level where respiratory abnormalities and arousals were minimised. Patients given continuous positive airway pressure used Sleep 
Table 1 Mean (SE) clinical features of treatment groups at baseline assessment

\begin{tabular}{llll}
\hline & CPAP $(n=21)$ & Control $(n=16)$ & $p$ \\
\hline Age (years) & $53(3)$ & $53(3)$ & $1 \cdot 00$ \\
Body mass index $\left(\mathrm{kg} / \mathrm{m}^{2}\right)$ & $34(2)$ & $32(2)$ & $0 \cdot 31$ \\
No of apnoeas and hypopnoeas/h slept & $57(6)$ & $49(6)$ & $0 \cdot 38$ \\
No of arousals/h slept & $54(5)$ & $45(6)$ & $0 \cdot 26$ \\
Minimum oxygen saturation (\%) & $61(5)$ & $69(4)$ & $0 \cdot 27$ \\
\hline
\end{tabular}

CPAP - continuous positive airway pressure.

Easy II or Sleep Easy III units, which were fitted with hidden time clocks.

Allocation to treatment groups was not randomised but was partially based on patients' preference. Half of the control group had declined to start continuous positive airway pressure while the other half were directly assigned to conservative treatment. All patients were given advice on weight loss and avoidance of evening alcohol. The clinical features of the two groups were similar (table 1).

\section{ASSESSMENT}

At each time of testing all patients underwent a multiple sleep latency test ${ }^{12}$ and on a nonconsecutive day a 3 hour battery of psychometric tests, including assessment of cognitive performance and mood, as detailed in table 2 . Both sessions were performed after the

Table 2 Psychometric battery

$\begin{array}{ll}\begin{array}{l}\text { Tests of general function } \\ \text { and of memory }\end{array} & \begin{array}{l}\text { WAIS subtests-information, } \\ \text { arithmetic, block design, } \\ \text { digit symbol substitution } \\ \text { TrailMaking tasks A and B } \\ \text { Auditory verbal learning test }\end{array} \\ \text { Premorbid level of function } & \begin{array}{l}\text { National adult reading test } \\ \text { Processing time }\end{array} \\ \text { Inspection time test } \\ \text { Simple unprepared reaction } \\ \text { time } \\ \text { Paced auditory serial } \\ \text { addition test (presentation } \\ \text { rates } 2 \mathrm{~s} \text { and } 4 \text { s) } \\ \text { Driving simulator } \\ \text { Hospital anxiety and } \\ \text { depression scale }\end{array}$

WAIS-Wechsler adult intelligence scale.

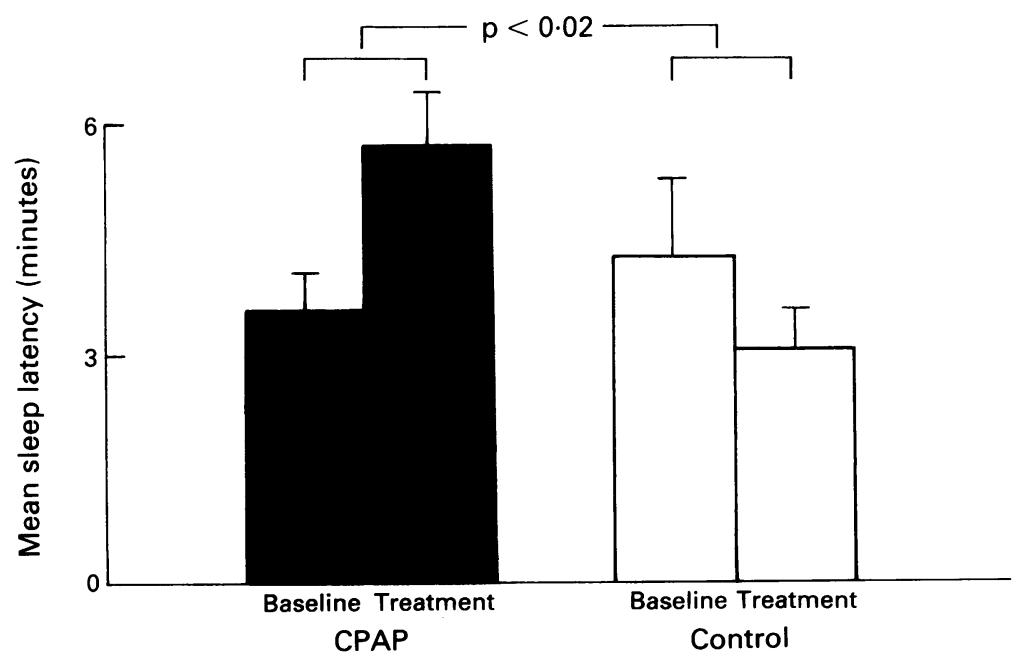

Mean sleep latency in patients with the sleep apnoea syndrome at baseline and after treatment with continuous positive airway pressure (CPAP) or after having been given advice alone (control). patient had slept the night in their own bed. Patients had only non-caffeinated drinks on the days of testing.

Because patients with the sleep apnoea/ hypopnoea syndrome tend to have arousals associated with apnoeas and hypopnoeas soon after sleep onset, the definition of sleep onset used in the multiple sleep latency test was modified to one 20 second epoch of any sleep stage. This definition of sleep onset in such patients has since been accepted by the American Sleep Disorders Association. ${ }^{13}$ The psychometric battery was designed to incor- 을 porate tests of a wide range of neuropsychological function, including general level of $\overrightarrow{0}$ function, visuomotor skill, concentration abil- $\overrightarrow{\vec{H}}$ ity, vigilance, memory, and mood. A standardised alternative to the word list in the $\overrightarrow{\vec{*}}$ auditory verbal learning test was used in the repeat testing session to obviate learning $\underset{6}{\infty}$ related improvements in score. ${ }^{14}$ The admin- 6 istration of the national adult reading test $\vec{\overrightarrow{ }}$ rendered an estimate of premorbid perfor- 윽 mance IQ. This estimate was subtracted from $\vec{c}$ the performance IQ score obtained from the $\mathbb{D}$ Wechsler adult intelligence scale performance $\frac{\vec{D}}{\mathbb{D}}$ subtests to calculate an "IQ decrement" score 3 for each patient. Overall change in cognitive $\stackrel{\mathbb{D}}{\square}$ function score for each individual was $\vec{\theta}$ assessed by using a summed $\mathrm{Z}$ score ${ }^{15}$ of each patient's performance in all cognitive tests in the battery.

\section{STATISTICS}

Data from the multiple sleep latency test and $\stackrel{\circ}{\triangleright}$ the psychometric tests were analysed by the BMDP package. ${ }^{16}$ Baseline values between $\frac{0}{3}$ the two groups were compared by Student's unpaired $t$ tests. Non-normally distributed data were examined using the Mann-Whitney $\mathrm{U}$ test. Two way analysis of variance was used to assess the interaction of the treatment and $\tilde{x}$ repeated test factors when examining the $\frac{\sigma}{3}$ change in cognitive function from baseline to the second assessment in the two groups.

\section{Results}

ALL PATIENTS

Comparison of treatment groups at baseline

There were no differences in psychometric $N$ function at baseline in the two groups. N However, the mean sleep latency on the multiple sleep latency test was longer in theo conservatively treated group (fig; $p=0.01$ ).

Within group changes in scores from first to second assessment

Both groups showed significant improve- $\frac{\stackrel{Q}{\Phi}}{\mathbb{D}}$ ments in scores in a wide range of psycho- $\stackrel{D}{2}$ metric function tests (table 3 ). There was also significant lengthening of sleep latency in the 8 multiple sleep latency test on the group? treated with continuous positive airway pres-흘 sure.

Comparison of change in scores from first to second assessment between the two groups There was no significant difference between the two groups in changes in any of the 
Table 3 Mean (SE) significant within group changes* from first to second assessment

\begin{tabular}{|c|c|c|c|c|}
\hline \multirow[b]{2}{*}{ Test } & \multicolumn{2}{|l|}{ CPAP group } & \multicolumn{2}{|l|}{ Control group } \\
\hline & Change & $p$ & Change & $p$ \\
\hline Information (no correct) & $1 \cdot 4(0 \cdot 4)$ & $<0.01$ & $0.9(0.4)$ & 0.05 \\
\hline $\begin{array}{l}\text { Digit symbol substitution } \\
\text { (no correct) } \\
\text { IO: }\end{array}$ & $3 \cdot 6(0 \cdot 9)$ & $<0.01$ & & \\
\hline $\begin{array}{l}\text { Verbal } \\
\text { Performance } \\
\text { Full }\end{array}$ & $2 \cdot 1(1 \cdot 0)$ & 0.05 & $\begin{array}{l}4 \cdot 0(1 \cdot 8) \\
5 \cdot 6(2 \cdot 1) \\
4 \cdot 6(1 \cdot 4)\end{array}$ & $\begin{array}{l}<0.05 \\
<0.05 \\
<0.01\end{array}$ \\
\hline $\begin{array}{l}\text { TrailMaking task B (s) } \\
\text { PASAT (no correct): }\end{array}$ & & & $-27 \cdot 3(2 \cdot 7)$ & $<0.01$ \\
\hline $\begin{array}{l}4 \mathrm{~s} \\
2 \mathrm{~s} \\
\text { Driving response time }(\mathrm{s})\end{array}$ & $\begin{array}{r}4 \cdot 3(1 \cdot 5) \\
5 \cdot 3(1 \cdot 7) \\
-6 \cdot 2(2 \cdot 4)\end{array}$ & $\begin{array}{r}0.01 \\
0.01 \\
<0.05\end{array}$ & $4 \cdot 7(1 \cdot 6)$ & $0 \cdot 01$ \\
\hline $\begin{array}{l}\text { Sleep latency (min): } \\
\text { Mean } \\
\text { Minimum }\end{array}$ & $\begin{array}{l}-0 \cdot 2(2 \cdot 4) \\
2 \cdot 1(0 \cdot 8) \\
1 \cdot 3(0 \cdot 5)\end{array}$ & $\begin{array}{r}0.01 \\
<0.05\end{array}$ & & \\
\hline
\end{tabular}

CPAP_continuous positive airway pressure; PASAT_paced auditory serial addition test. *All significant changes were in the direction of improvement in the tests concerned.

psychometric function tests $(p>0 \cdot 2)$. Mean sleep latency lengthened significantly in the treated group compared with the control group ( $p<0.02 ;$ fig). Similarly, the treated group had a trend to greater improvement in the shortest of the five sleep latencies during the multiple sleep latency test $(p>0 \cdot 05)$.

\section{GOOD COMPLIERS}

The hidden time clocks in the continuous positive airway pressure units allowed an average nightly usage to be calculated for each patient. The mean (SE) usage for the group was $5.9(1.4)$ hours per night. We divided the group treated with continuous positive airway pressure into those who complied well with treatment and used their units for more than 4.5 hours per night $(n=14)$ and those who used it for less than 4.5 hours per night. The results for the good compliers were compared with those for the controls. The good compliers again showed significantly greater improvements in mean sleep latency compared with the conservatively treated patients (visit $1: 3.4(0.5)$ minutes, visit 2: $5.5(0.4)$ minutes; $p<0.05)$ and shortest sleep latency (visit $1: 1.3(0.3) \mathrm{min}-$ utes, visit 2: $2 \cdot 4(0.3)$ minutes; $\mathrm{p}<0.05)$. The good compliers also showed a significantly greater improvement in depression score $(p=0.05)$ but no significant improvements in any cognitive function assessment compared with the control group.

There was no difference between the treated and control group in the change in weight during the study period (treated gained $1.4(0.6) \mathrm{kg}$, control gained $1.6(1 \cdot 3) \mathrm{kg})$.

\section{Discussion}

This study shows that treatment with continuous positive airway pressure results in improvements in objective sleepiness and may improve mood in good compliers, but we were unable to show any improvement in cognitive performance. We thus confirm the findings of Lamphere et al of an improvement in objective daytime sleepiness with continuous positive airway pressure, although our changes are much less dramatic than those of Lamphere et al. ${ }^{6}$ In part, this may reflect differences in criteria of defining sleep onset during the daytime naps, which we defined as a first 20 second epoch of any sleep stage rather than the first minute of any sleep stage to detect short sleep episodes rapidly disrupted by apnoeic arousals. Our data showing a moderate improvement in sleep latency with continuous positive airway pressure come midway between the dramatic improvements reported by Lamphere et $a l^{6}$ and the lack of improvement with continuous positive airway pressure or uvulopalatopharyngoplasty, or both, recently reported by Sangal $e t$ al. ${ }^{17}$ Although our different criteria for sleep onset might change the absolute value of multiple sleep latency in comparison with earlier studies, ${ }^{6}$ it is difficult to see how this could adversely affect our ability to detect improvement with continuous positive airway pressure. We have confirmed the results of Derderian et al that the treatment may improve mood. ${ }^{7}$

There has been a relative paucity of data on the effects of continuous positive airway pressure on cognitive performance. In a provisional report Bearpark et al found improvements in scores in visual memory, verbal fluency, and mental set flexibility on retesting after 4-5 months of continuous positive airway pressure, but their study had no control group to evaluate the effects of learning on performance. ${ }^{18}$ Similarly, Charbonneau et al have reported improved cognitive function with the treatment in an uncontrolled study. ${ }^{19}$ Our finding of within group improvements in cognitive performance on retesting in both groups shows that a learning curve exists for cognitive function tests. It also indicates the need for control groups in such studies and shows that the conclusions of Bearpark et al ${ }^{18}$ and Charbonneau et $a l^{19}$ that continuous positive airway pressure improves psychometric function cannot be drawn from their studies. Our studies are consistent with the observation of Walsleben et al, who found no improvement in cognitive function after two nights of continuous positive airway pressure treatment in a small study $(n=7) .^{3}$

The lack of demonstrable improvement in cognitive function in our study could be due to our choice of psychometric performance tests, to the wide interindividual variability, to poor compliance with treatment, or to the fact that there genuinely is no improvement in cognitive function which might be permanently impaired in patients with the sleep apnoea/hypnoea syndrome. We chose the psychometric function tests to reflect the abnormalities that we have previously detected in patients with the syndrome ${ }^{11}$ and to cover a wide range of cognitive functions. Our patients were well within the operating range for all the cognitive function tests and thus the lack of an improvement was not due to there being no room for improvement in their results. We believe that the battery of 
tests used is fairly comprehensive. Nevertheless, Findley et al have shown improvement in a long and repetitive task designed to simulate driving, ${ }^{20}$ although it remains to be seen whether this reflects improved cognitive function, a decrease in daytime microsleeps, or improved performance with greater familiarity with the task. We believe that the large interindividual variability in cognitive function may have resulted in our failure to find differences in a parallel group design such as we used. We are thus initiating a crossover study of the effect of continuous positive airway pressure or placebo on objective daytime sleepiness, cognitive function and mood. Compliance with treatment was somewhat disappointing in our study, with a mean use of continuous positive airway pressure of 5.9 hours/night. We suggest, however, that this probably reflects use in the community and is certainly in keeping with other recent studies which have objectively examined compliance in patients with the sleep apnoea/hypnoea syndrome. ${ }^{21} 22$

This study shows that there are significant improvements in both objective daytime sleepiness and mood with continuous positive airway pressure in patients with the sleep apnoea/hypopnoea syndrome, but we found no evidence of major improvements in cognitive function with such treatment.

We thank Sisters C Hoy and M Vennelle and Ms K Stedul and $\mathrm{H}$ Biernacka for technical and nursing help and Mrs $E$ Dolan for preparing the manuscript.

1 Greenberg GD, Watson RK, Deptula D. Neuropsychological dysfunction in sleep apnea. Sleep 1987;10:254-62.

2 Findley LJ, Barth JT, Powers DC, Wilhoit SC, Boyd DG, Suratt PM. Cognitive impairment in patients with obstructive sleep apnea and associated hypoxemia. Chest 1986;90:686-90.

3 Walsleben JA, Squires NK, Rothenberger VK. Auditory event related potentials and brain dysfunction in sleep apnea. Electroencephalogr Clin Neurophysiol 1989;74: 297-311.
4 Sullivan CE, Berthon-Jones M, Issa FG, Eves L. Reversal of obstructive sleep apnoea by continuous positive airway pressure applied through the nares. Lance 1981;i:862-5

5 Sanders MH. Nasal CPAP effect on patterns of sleep apnea. Chest 1984;86:839-44.

6 Lamphere J, Roehrs T, Wittig R, Zorick F, Conway WA, Roth $\mathrm{T}$. Recovery of alertness after CPAP in apnea. Chest 1989;96:1364-7.

7 Derderian SS, Bridenbaugh RH, Rajagopal K. 孚 Neuropsychologic symptoms in obstructive sleep apnea improve after treatment with nasal continuous positive $\overline{\bar{F}}$ airway pressure. Chest 1988;94:1023-7.

8 Gould GA, Whyte KF, Rhind GB, Airlie MAA, Catterall ${ }^{\circ}$ JR, Shapiro CM, et al. The sleep hypopnea syndrome. 흐 Am Rev Respir Dis 1988;137:895-8.

9 Douglas NJ, Thomas S, Jan MA. Clinical value of $\frac{\widehat{D}}{\mathbb{D}}$ polysomnography. Lancet 1992;339:347-50.

10 Rechtschaffen A, Kales A, eds. A manual of standardized terminology, techniques and scoring system for sleep stages of $\mathcal{C}$ human subjects. Bethesda: National Institutes of Health, $\overrightarrow{0}$ 1968.

11 Cheshire K, Engleman H, Deary I, Shapiro C, Douglas $\overrightarrow{\vec{\omega}}$ NJ. Factors impairing daytime performance in patients with sleep apnea/hypopnea syndrome. Arch Intern Med 1992;152:538-41.

12 Carskadon MA, Dement WC, Mitler MM, Roth T, $\stackrel{\infty}{\infty}$ Westbrook PR, Keenan S. Guidelines for the multiple sleep latency test (MSLT): a standard measure of sleepiness. Sleep 1986;9:519-24.

13 Thorpy MJ. Report from the American Sleep Disorders $\vec{A}$ Association. The clinical use of the multiple sleep 음 latency test. Sleep 1992;15:268-76.

14 Crawford JR, Stewart LE, Moore JW. Demonstration of savings on the AVLT and development of a parallel $\Phi$ form. F Clin Exp Neuropsychol 1989;11:975-81.

15 Lezak M. Neuropsychological assessment. 2nd ed. Oxford: Oxford University Press, 1983:138.

16 Dixon WJ, ed. BMDP statistical software manual. Berkeley: University of California Press, 1988.

17 Sangal RB, Thomas L, Mitler MM. Disorders of excessive $\vec{\theta}$ sleepiness: treatment improves ability to stay awake but does not reduce sleepiness. Chest 1992;102:699-703.

18 Bearpark H, Grunstein R, Touyz S, Channon L, Sullivan C. Cognitive and psychological dysfunction in sleep apnea before and after treatment with CPAP. Sleep Res 1987;16:303

19 Charbonneau M, Tousignant P, Lamping DL, Cosio ڤ్ MG, Montserrat JM, Olha AE, et al. The effects of $\mathbb{D}$ nasal continuous positive airway pressure (nCPAP) on $\varrho$ sleepiness and psychological functioning in obstructive $\overrightarrow{\vec{D}}$ sleep apnea (OSA). Am Rev Respir Dis 1992;145:A168.

20 Findley L, Fabrizio M, Knight H, Norcross B, Laphorte A, Suratt P. Driving simulator performance in patients with sleep apnea. Am Rev Respir Dis 1989;140:529-30.

21 Fletcher EC, Luckett RA. The effect of positive reinforcement on hourly compliance in nasal continuous positive airway pressure users with obstructive sleep apnea. $A m$ Rev Respir Dis 1991;143:936-41.

22 Reeves-Hoche MK, Meck R, Zwillich CW. Long-term ó compliance with nasal continuous positive airway pressure therapy. Am Rev Respir Dis 1992;145:A169. 